\title{
Analysis on the Fault Trip of 27du/dt Protection and Countermeasure in Gaozhao HVDC
}

\author{
Huang Yi-Long and Zhou Quan
}

\begin{abstract}
With the replay of the de voltage fault record, this paper analyzes the trip of dc line under-voltage sensing protection(27du/dt) caused by ac system fault in Gaozhao HVDC on December 15, 2012 and June 18,2008. The paper brings in the protection enabled condition and analyzes the impact of its broadening time to $27 \mathrm{du} / \mathrm{dt}$ protection. The improved scheme which adds the protection enabled condition and modifies the return voltage of boot logic is presented. The simulation results show that the scheme can avoid the fault trip of $27 \mathrm{du} / \mathrm{dt}$ protection in Gaozhao HVDC.
\end{abstract}

Index Terms-AC system fault, 27du/dt protection, protection enabled condition, broadening time, protection threshold.

\section{INTRODUCTION}

On December 15, 2012, the voltage of the bipolar ac feeder line and the dc line both declined in Zhaoqin Station of Gaozhao HVDC, dued to the facility fault in Yandu $500 \mathrm{kV}$ Station. The three sets of dc line undervoltage sensing protection $(27 \mathrm{du} / \mathrm{dt}$ protection) of Pole 1 and the first set of Pole 2 acted simultaneously. Then the bipolar dc line fault recovered and operated at $350 \mathrm{kV}$.

Tracing the operation history records, on June 18, 2008, Gaopo Station of Gaozhao HVDC had the similar event that the three sets of $27 \mathrm{du} / \mathrm{dt}$ protection acted because of the ac system fault. Although the protection software complied with the design logic, it went against the design principle that dc protection should not act reliably during ac system fault period [1]-[6]. Additionally, during the Gaozhao HVDC DPT test, the similar event also appeared. According to the problem of $27 \mathrm{du} / \mathrm{dt}$ protection, the improved measures are presented, which use ac bus voltage, information of pole control and $\mathrm{dc}$ line differential current as additional criterion, to block the $27 \mathrm{du} / \mathrm{dt}$ protection during ac system fault period. But considering it is long to implement improved protection software, the temporary measure is implemented instead, which increases the delay time of protection based on the existing protection logic [7]-[8].

Seen from the event on December 15, 2012, the measure of increasing the delay time cannot fully avoid the fault trip of $27 \mathrm{du} / \mathrm{dt}$ protection. Therefore, more effective improved measures need to take. The paper studies the experience of setting protection enabled condition of $27 \mathrm{du} / \mathrm{dt}$ protection from Xingan and Chusui HVDC, and improves the existing protection logic of $27 \mathrm{du} / \mathrm{dt}$ protection in Gaozhao HVDC,

Manuscript received February 28, 2013; revised June 22, 2013

Huang Yi-Long and Zhou Quan are with China Southern Power Grid EHV Maintenance \& Test Center, China (e-mail: sw.hyl@163.com, zhouquan236@163.com). adds the protection enabled condition and modifies the return voltage of the boot logic. The replay of the record wave shows that the setting of protection enabled condition can avoid the fault trip of $27 \mathrm{du} / \mathrm{dt}$ protection effectively, and appropriately reducing its broadening time has better effect.

\section{COMPARISON TO THE PRINCIPLE OF 27DU/DT PROTECTION}

$27 \mathrm{du} / \mathrm{dt}$ protection is the backup protection of dc line wavefront protection, and it uses du/dt and low voltage as the detection quantity [9]-[13]. Its principle and threshold are shown in Table I.

From the table we can see, the principle of $27 \mathrm{du} / \mathrm{dt}$ protection is basically consistent in Gaozhao, Xingan, Chusui HVDC. The only difference between Gaozhao and Xingan HVDC is Xingan HVDC has the protection enabled condition. Chusui and Xingan HVDC both have the protection enabled condition, but there is a bit different. The dc voltage of Chusui HVDC gets the maximum between the current value and the value $5 \mathrm{~ms}$ before without setting the broadening time, but it like setting the boot high level to $5 \mathrm{~ms}$ when voltage drops from high to low.

\section{ApPLICATION OF PRotection ENABLED CONDITION}

Take 27du/dt protection in Xingan HVDC for example, shown in Fig. 1, UVP25 and UVP50 are AND logic modules; UVP60 is OR logic module; UVP10 is multiply logic module. UVP20 and UVP40 is comparison module; UVP30 is impulse equal module; UVP45 is fall edge broadening module; UVP75 is rise edge broadening module; UVP70 is RS flip-flop; the logic characteristic of these modules are illustrated in Fig. 2.

Shown in Fig. 1, the protection enabled condition logic is inside the dashed frame; the $\mathrm{A} 1 \mathrm{~A} 2$ part realizes the protection boot logic function; B1B2 part realizes the protection reset logic function. The purpose of the protection enabled condition focuses on restricting the sensitivity of $27 \mathrm{du} / \mathrm{dt}$ protection, which embodies in the setting of broadening time. The longer the broadening time is, the higher the action sensitivity is, and otherwise the lower.

The setting of ON voltage and OFF voltage makes sure that $27 \mathrm{du} / \mathrm{dt}$ protection may act when voltage drops from high to low. This setting is realized by the comparison module. And it can avoid the fault trip of $27 \mathrm{du} / \mathrm{dt}$ when voltage jumps from low and then fall again during the late period of fault. 
TABLE I: PRINCIPLE AND Threshold of 27DU/DT PRotection IN GAOZHAO, Xingan AND ChuSUI HVDC

\begin{tabular}{|c|c|c|c|c|}
\hline HVDC & Principle & threshold & Delay time & protection enabled condition \\
\hline Gaozhao & $\begin{array}{l}\mathrm{UdL}<\Delta \\
\& \mathrm{du} / \mathrm{dt}>\Delta\end{array}$ & $\begin{array}{l}\text { On UdL: } 25 \% \\
\text { Off UdL: } 40 \% \\
\text { du/dt: } 10 \%\end{array}$ & $110 \mathrm{~ms}$ & \\
\hline Chusui & $\begin{array}{l}\mathrm{UdL}<\Delta \\
\& \mathrm{du} / \mathrm{dt}>\Delta\end{array}$ & $\begin{array}{l}\text { On UdL (sigle): } 20 \% \\
\text { Off UdL ( sigle): } 40 \% \\
\text { On UdL (double): } 35 \% \\
\text { Off UdL (double): } 60 \% \\
\text { du/dt: } 14 \%\end{array}$ & $100 \mathrm{~ms}$ & $\begin{array}{l}\mathrm{UdL}(\text { single })>40 \% \text {, UdL(double })>60 \% \text {, no } \\
\text { broadening, but UdL gets the maximum } \\
\text { between the current value and the value } 5 \mathrm{~ms} \\
\text { before }\end{array}$ \\
\hline
\end{tabular}

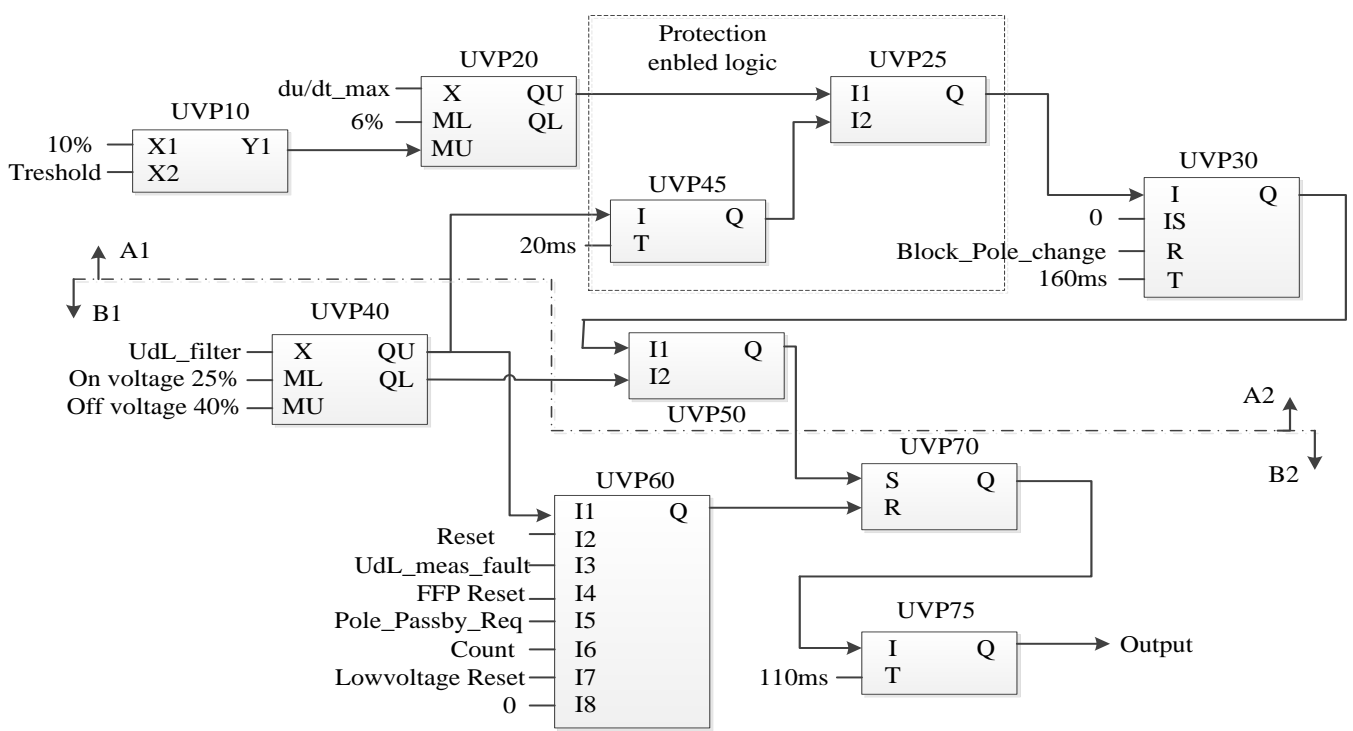

Fig. 1. Logic of $27 \mathrm{du} / \mathrm{dt}$ protection in Xingan HVDC.

The filtered dc voltage UdL is put into the comparison choose module UVP40. When dc voltage drops below $25 \%$ from normal value, the output pin QU changes from high level to low level, but the high level broadens $20 \mathrm{~ms}$ by the fall edge broadening module. In this period when $\mathrm{du} / \mathrm{dt}$ reach threshold, protection enables and the boot logic becomes high level. Then $S=1, R=0$, RS flip-flop exports high level, and $27 \mathrm{du} / \mathrm{dt}$ protection acts in $110 \mathrm{~ms}$ later. Because RS flip-flop has the function of output keeping, after protection acting the protection output signal will sustain, even if the boot signal disappears.
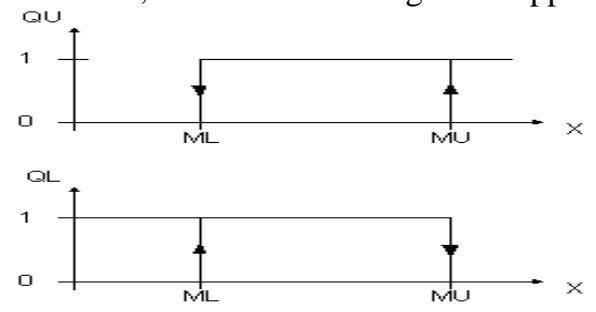

(a) Characteristic of comparison module

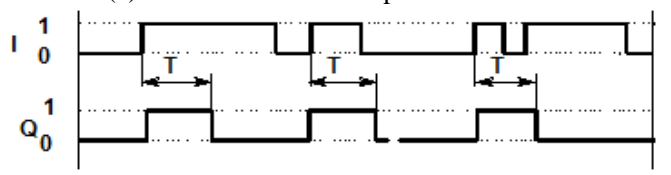

(b) Characteristic of impulse equal module

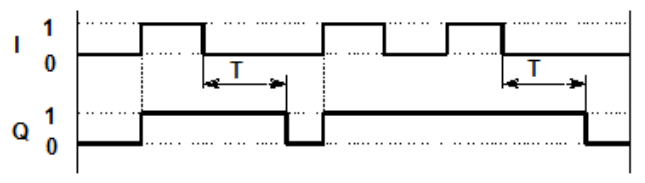

(c) Characteristic of fall edge broadening module

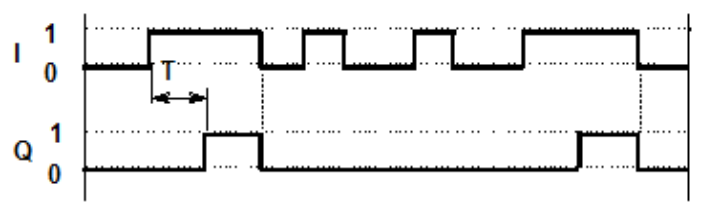

(d) Characteristic of fall edge broadening module

\begin{tabular}{c|c|c|c|c}
\hline $\mathrm{S}$ & 0 & 0 & 1 & 1 \\
\hline $\mathrm{R}$ & 0 & 1 & 0 & 1 \\
\hline $\mathrm{Q}$ & sustained & 0 & 1 & 0 \\
\hline \multicolumn{4}{c}{ (e) Characteristic of RS flip-flop }
\end{tabular}

Fig. 2. Logic characteristic of modules.

\section{Analysis on Broadening Time of Protection ENABLED CONDITION}

Seen from the fault trip of $27 \mathrm{du} / \mathrm{dt}$ protection events in Gaozhao HVDC, the sensitivity of the protection is too high, and the probability of satisfying the threshold of $\mathrm{du} / \mathrm{dt}$ and low voltage meanwhile is a bit high. So $27 \mathrm{du} / \mathrm{dt}$ protection is easy to trip incorrectly. Therefore it is necessary to add the protection enabled condition. This section analyses the dc voltage record wave of $27 \mathrm{du} / \mathrm{dt}$ protection fault trip in Gaozhao HVDC on December 15, 2012 and June 18, 2008. And the impact of broadening time of protection enabled condition on $27 \mathrm{du} / \mathrm{dt}$ protection is discussed.

\section{A. Replay of $27 d u / d t$ Protection Fault Trip on December 15, 2012}

The dc voltage record wave of rectifier station in Gaozhao HVDC is replayed in the RTDS. The voltage 
wave and the replay results are similar in pole 1 and pole 2. Take the pole 1 record wave for example. $27 \mathrm{du} / \mathrm{dt}$ protection acts before the logic is modified. Reference to the protection logic of Gaozhao HVDC, the protection enabled condition is added and the $27 \mathrm{du} / \mathrm{dt}$ protection does not act. The dc voltage TRACE record wave after filtered is illustrated in Fig. 3 (The longitudinal axis in the record wave figures are scaled in percentage).

From Fig. 3 and Fig. 4 we can see, voltage enabled condition satisfies the threshold $25 \%$ in about $-150 \mathrm{~ms}$, and the broadening time is $20 \mathrm{~ms}$, that is the enabled condition sustains until $-130 \mathrm{~ms}$, while du/dt will reach the threshold in about $-122 \mathrm{~ms}$. Therefore after modification $27 \mathrm{du} / \mathrm{dt}$ protection does not act. The two condition will satisfy simultaneously only with a $8 \mathrm{~ms}$ time gap, which lead to the action of $27 \mathrm{du} / \mathrm{dt}$ protection.

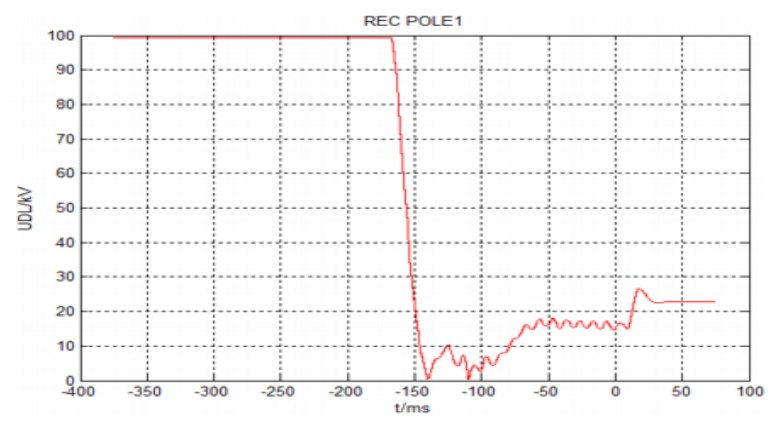

Fig. 3. DC voltage TRACE record wave after filtered.

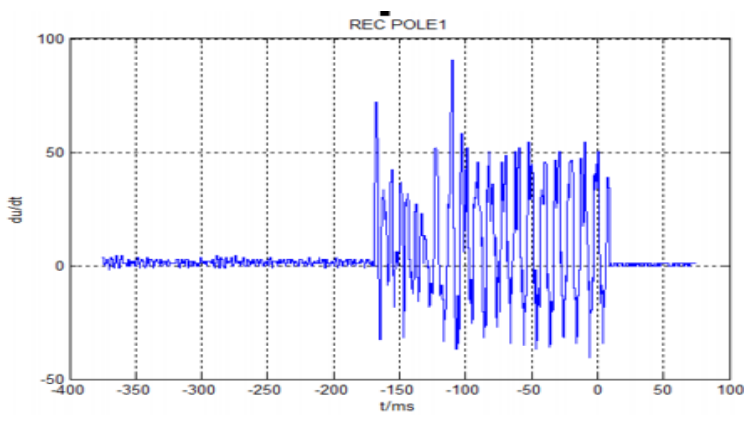

Fig. 4. du/dt TRACE record wave.

B. Replay of $27 d u / d t$ Protection Fault Trip on June 18, 2008

The dc voltage record wave of rectifier station in Gaozhao HVDC is replayed in the RTDS. The voltage wave and the replay results are similar in pole 1 and pole 2. Take the pole 1 record wave for example. The dc voltage TRACE record wave after filtered is illustrated in Fig. 5.

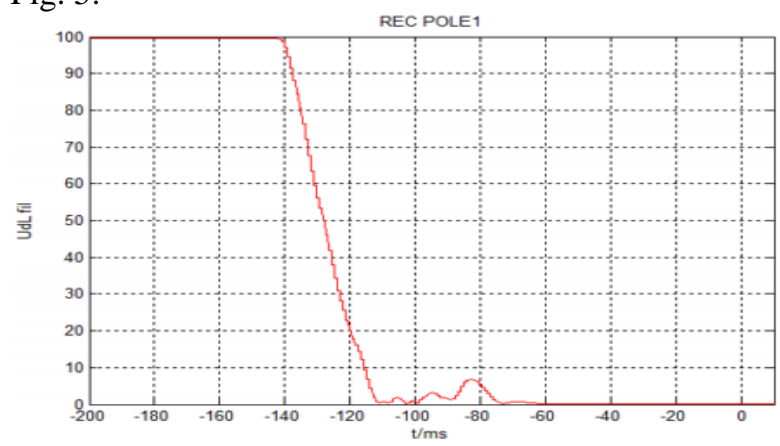

Fig. 5. DC voltage TRACE record wave after filtered.

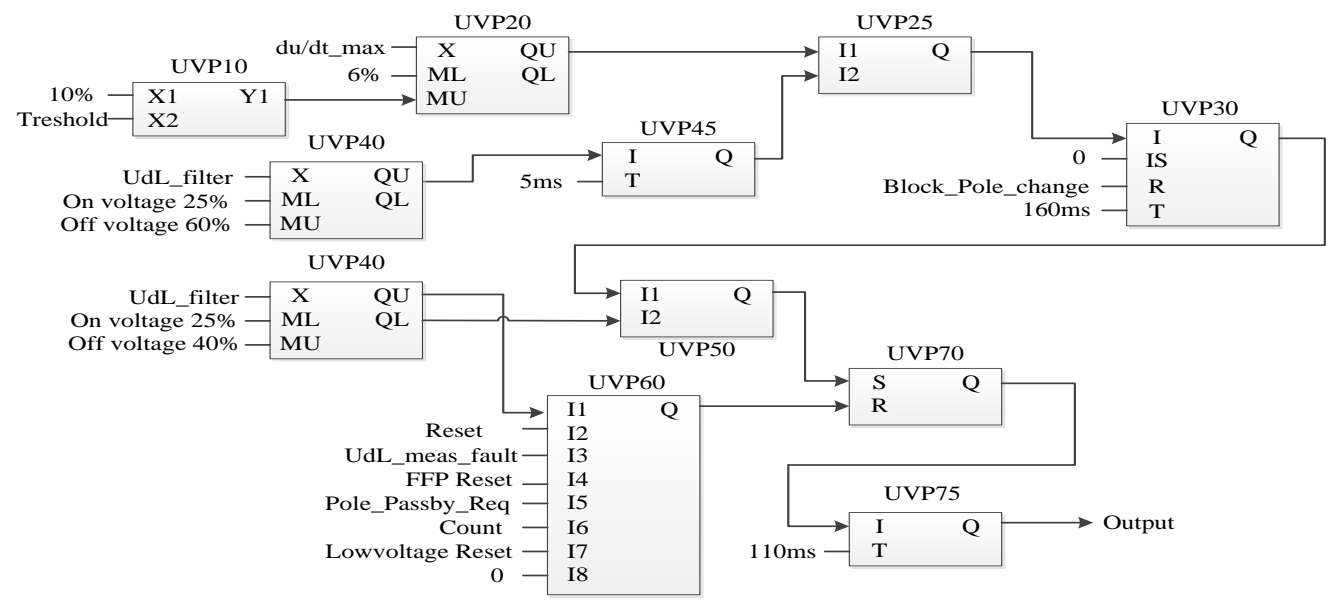

Fig. 7. Logic of 27du/dt protection after modified in Gaozhao HVDC.

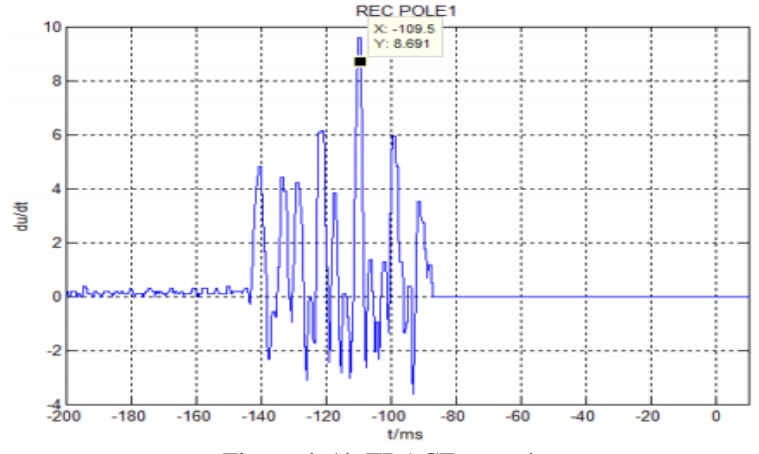

Fig. 6. du/dt TRACE record.

From Fig. 5 and Fig. 6 we can see, voltage enabled condition satisfies the threshold $25 \%$ in about $-121 \mathrm{~ms}$, and the broadening time is $20 \mathrm{~ms}$, that is the enabled condition sustains until $-101 \mathrm{~ms}$, while du/dt reach $9.57 \%$ in about $-110 \mathrm{~ms}$. There is only a $11 \mathrm{~ms}$ time gap before the $\mathrm{du} / \mathrm{dt}$ and low voltage reach threshold simultaneously. If the broadening time is set below $10 \mathrm{~ms}$, the $27 \mathrm{du} / \mathrm{dt}$ protection will not act at this situation.

From the replay results of the two events, we can figure out that adding the protection enabled condition is benefited to avoid the fault trip of $27 \mathrm{du} / \mathrm{dt}$ protection caused by ac system fault, and reducing the broadening time of protection enabled condition can improve the validity of the action of $27 \mathrm{du} / \mathrm{dt}$ protection. 


\section{27DU/DT PROTECTION IMPROVED SCHEME}

In order to avoid the situation that dc voltage falls after immediately jump during the late period of fault, which leads to the fault trip of $27 \mathrm{du} / \mathrm{dt}$ protection, it is advised to raise the OFF voltage of boot logic. So it needs to separate the boot logic and the reset logic. Analysis on the replay of the record wave shows the effectiveness of adding protection enabled condition and modifying its broadening time. After comprehensive consideration, specific improvement measures are presented as follows.

1) Setting the protection boot logic and reset logic apart.

2) For the boot logic, the OFF voltage change from $40 \%$ to $60 \%$, but the ON voltage sustains.

3) Adding the protection enabled condition and setting the broadening time to $5 \mathrm{~ms}$, instead of $20 \mathrm{~ms}$ in Xingan HVDC.

The modified logic of $27 \mathrm{du} / \mathrm{dt}$ protection in Gaozhao HVDC is shown in Fig. 7. The simulation results show that the improved scheme can avoid the fault trip of $27 \mathrm{du} / \mathrm{dt}$ protection in Gaozhao HVDC on December 15, 2012 and June 18, 2008.

\section{CONCLUSIONS}

On June 18, 2008 the $27 \mathrm{du} / \mathrm{dt}$ fault trip event caused by ac system fault happened in Gaozhao HVDC. Then on December 15, 2012 Gaozhao HVDC happened the similar event again, which illustrates the improved measures of modifying the protection delay time is not effective. It disobeys the designed principle that dc line protection should not act reliably during ac system fault period. This paper analyses the two events by the replay of dc voltage record wave, and figures out that, adding protection enabled condition and reducing the broadening time can avoid the fault trip of $27 \mathrm{du} / \mathrm{dt}$. The improved scheme of adding protection enabled condition and modifying the ON voltage in the boot logic is presented. Simulation results verify the effectiveness of the improved scheme.

\section{REFERENCES}

[1] X. M. Gao, P. Zhang, and Z. He, "Analysis of the HVDC DC line protection," Automation of Electric Power Systems, vol. 29, no. 14, pp. 96-99, 2005.

[2] Z. Ding and W. Q. Han, "Summary of bipolar operation situation of Tian-Guang DC power transmission system," Power System Technology, vol. 27, no. 9, pp. 49-54, 2003.

[3] D. Liu and Z. H. Wu, "Analysis on the Tian-Guang DC line protection against high-impedance ground aults," Southern Power System Technology Research, vol. 1, no. 5, pp. 57-60, 2005.

[4] T. X. Zhu and K. J. Ou, "Research on earth fault process of high-voltage direct-current transmission lines," Guangdong Electric Power, 2008, vol. 21, no. 10, pp. 53-57.

[5] Y. Tao, Y. Long, and W. Han, "Status and development of HVDC control and protection," High Voltage Engineering, vol. 30, no. 11, pp. 8-10, 2004.

[6] L. Ai and W. H. Chen, "Discussion on line protection of HVDC transmission line," Relay, vol. 32, no. 4, pp. 61-63, 2004.

[7] J. Yu, H. Y. Zhou, and J. Y. Huang et al., "Analysis on HVDC Line Protection Action due to AC System Fault," Southern Power System Technology, vol. 3, no. 3, pp. 20-23, 2009.

[8] Q. Guo, W. Q. Han, and L. B. Huang et al., "RTDS simulation on evaluation of delay time settings of DC Under-Voltage Protection," Southern Power System Technology, vol. 3, no. 2, pp. 32-34, 2009.

[9] X. L. Chen, T. X. Zhu, and H. Zhou, "Research on Adjustment of Criterion Settings of DC Line Under-Voltage Protection," Power System Protection and Control, vol. 39, no. 9, pp. 125-130, 2011.

[10] Y. Y. Hu and D. C. Huang, "Faults and protection analysis of Gezhouba-Nanqiao DC transmission line," Automation of Electric Power Systems, vol. 32, no. 8, pp. 102-107, 2008.

[11] Q. Tian, "Analysis on the fault trip of bipole DC line protection in tianguang HVDC," High Voltage Apparatus, vol. 48, no. 4, pp. 33-38, 2012 .

[12] W. J. Zhao, HVDC transmission technology, Beijing: China Electric Power Press, 2011.

[13] X. Huifan, W. Haijun, Z. Nan, L. Zhiliang, and C. Qian, "China southern power grid EHV maintenance," in High Voltage Equipment Foundation, Beijing: China Electric Power Press, 2010

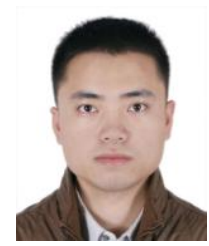

Huang Yi-Long was born in 1989, he is an engineering master, he majored in power system and its automation, he worked in China Southern Power Grid EHV Maintenance \& Test Center, engaged in maintenance of control and protection system in HVDC. 